\title{
Future with Wireless Power Transfer Technology
}

\section{Farhana Haque Sumi ${ }^{1 *}$, Lokesh Dutta ${ }^{2 *}$, Dr. Farhana Sarker ${ }^{3 *}$}

${ }^{1}$ Department of Computer Science and Engineering, University of Liberal Arts Bangladesh, Bangladesh ${ }^{2}$ Department of Computer Science and Engineering, Maharshi Dayanand University Rohtak, India

${ }^{3}$ Department of Computer Science and Engineering, University of Liberal Arts Bangladesh, Bangladesh

\begin{abstract}
Wireless power transmission is the way to transfer power without using wire. Wireless power transmission helps to connect those area where people are unable to get a suitable power source. Everyone can get clean and green wireless power. In future all the devices will relate to the power supply source wirelessly. In this paper we have presented the successful experimental attempts to transmit power wirelessly and future scope of wireless power transmission. We have tried to represent the future use of wireless power transmission in various areas where wired power transmission is impossible to supply implement.
\end{abstract}

Keywords: Wireless power transmission, Solar power satellite; Electromagnetic field; Magnetic fields; Electrical vehicle; Power beaming

\section{Introduction}

In the whole world electricity transfer from power station to everywhere is through wire. Wireless power transfer technology can potentially reduce or eliminate the need for wires and batteries. Wireless transmission is useful to power electrical devices where interconnecting wires are inconvenient, hazardous, or are not possible. Wireless power transfer technology reduces the use of electric wire which is made of copper and aluminum metal. The metal which are used to make electric wire will extinct in future. If we implement wireless power transfer technology the use of electric wire will reduce. It would be beneficial if in future, we can implement wireless power transfer technology to transfer power from power station to everywhere without the need of wire. In section 2 different categories of wireless power technique are discussed, whereas in section 3 represents the various experimental proof of wireless power transfer, section 4 discusses different applications of wireless power transfer and finally section 5 discusses the potential future application of wireless power transfer technology.

\section{Wireless Power Technique Categories}

\section{Non- radiative}

In near field or non-radiative techniques, by magnetic fields using inductive coupling between coils of wire power is transferred over short distances, or by electric fields using capacitive coupling between metal electrodes. In wireless technology, inductive coupling is widely used; phones and electric toothbrushes, RFID tags, and chargers for implantable medical devices like artificial cardiac pacemakers, or electric vehicles are included its application [1].

Near-field transfer: In near-field transfer coupling of two coils are needed to transfer power. Through magnetic field coupling a transformer is transferring energy wirelessly, although it was invented more than 100 years ago. The transfer efficiency drops drastically if we remove the iron core and move the two coils apart [2]. That is why the two coils must be put close enough to each other. This kind of method is already launched in the market. For example, most electric toothbrushes are using wireless chargers, which are much safer than cable chargers in wet environment [3].

The frequency of the transmitter and receiver coils is determined by the material and shape of the coil, transfer efficiency will decrease much more slowly when they are moved apart. Prof. Marin Soljacic led a group from MIT, has succeeded in transferring electric energy (60 Watt) between two coils more than two meters apart through nonradiative electromagnetic field, as shown in Figure 1 [4]. There is almost no interference with $\mathrm{TV}$, radio or Wi-Fi signals and it happens in near field usually working at 50 or $60 \mathrm{~Hz}$. The major problem the possibility of influence on human health. But one thing is that almost all materials that form human body are non-magnetic, so they cannot interact with magnetic field, even to several Tesla like that in a modern MRI machine $[4,5]$. Such kind of magnetic-field-is there that is quite safe to people within the transfer range [3].

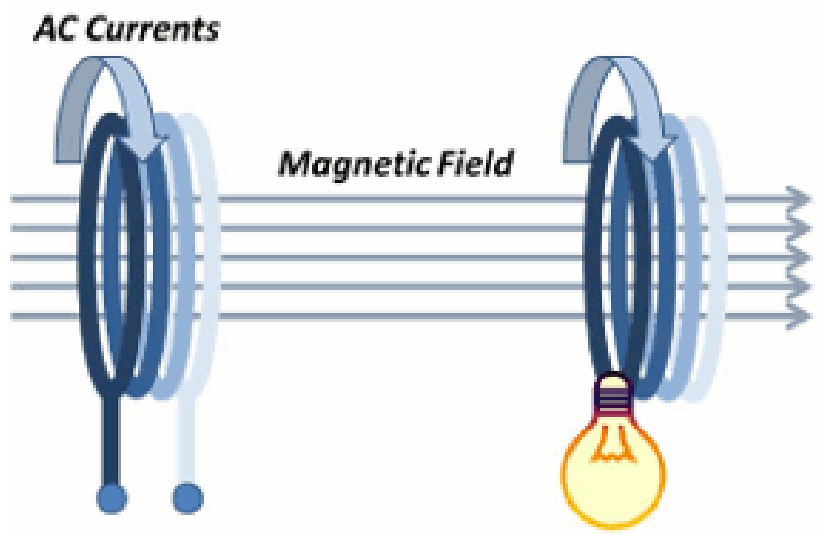

Figure 1: Transferring energy through magnetic field coupling between two coils with identical resonant frequency.

*Corresponding author: Sumi FH, Department of Computer Science and Engineering, University of Liberal Arts, 20/15 Tolarbagh, Mirpur-1, Dhaka-1216, Bangladesh, India, Tel: +8801632379976; E-mail: farhana.haque.cse@ulab.edu.bd

Received October 04, 2018; Accepted October 29, 2018; Published November 05, 2018

Citation: Sumi FH, Dutta L, Sarker F (2018) Future with Wireless Power Transfer Technology. J Electr Electron Syst 7: 279. doi: 10.4172/2332-0796.1000279

Copyright: ( 2018 Sumi $\mathrm{FH}$, et al. This is an open-access article distributed under the terms of the Creative Commons Attribution License, which permits unrestricted use, distribution, and reproduction in any medium, provided the original author and source are credited. 


\section{Radiative}

In far-field or radiative techniques, power is transferred by beams, like microwaves or laser beams also called power beaming. Power beaming techniques can transport energy longer distances. Solar power satellites, and wireless powered drone aircraft are proposed applications [6-8].

Far-field transfer: To transfer energy wirelessly over long ranges, far-field transfer is used.

- Microwaves: In far-field radiative electromagnetic wave is used. Different method uses electromagnetic waves within different wave band. In the early times, there were many experiments with radio and microwaves [9]. To achieve sufficient directionality, the wavelength of the antennas must be longer. An antenna with a dimension of several meters to several kilometers which requires the speed of light in the air is about $3 \times 10^{8} \mathrm{~m} / \mathrm{s}$ and the wavelength of radio and microwaves is about 1 meter. To transfer energy to smaller objects shorter wavelength is used. The electromagnetic wave used the waveband of radio, TV, cell phone and $\mathrm{Wi}-\mathrm{Fi}$, with a signal intensity several orders of magnitude larger [10].

- Lasers: In the case of electromagnetic field show in Figure 2 power can be transmitted by converting electricity into a laser beam. That is then pointed at a photovoltaic cell $[11,12]$. In the case the power is beamed at a receiver that can convert it to electrical energy, so this mechanism is generally known as 'power beaming' technology. Special photovoltaic laser power converters are optimized for monochromatic light conversion that are applied at the receiver [13]. This technology used in military weapons $[14-16]$ and aerospace $[17,18]$ applications.

\section{Various Experimental Proof of Wireless Power Transfer}

- Resonant inductive coupling, also known as "electro-dynamic induction" used by Nikola Tesla in 1894 to wirelessly light up phosphorescent and incandescent lamps. That was situated at the 35 South Fifth Avenue laboratory, and later at the $46 \mathrm{E}$. Houston Street laboratory in New York City [19-21]. A device [22] called the high-voltage was patented by Nikola Tesla in 1897.

- In 1910 an experiment was held using incandescent light powered wirelessly by electromagnetic induction. The bottom of a large cylinder was made by using an electromagnet, a coil of wire with alternating current through it. It creates a magnetic field. Above the magnet's pole the lamp is attached to another coil of wire. The magnetic field generate electricity that lights

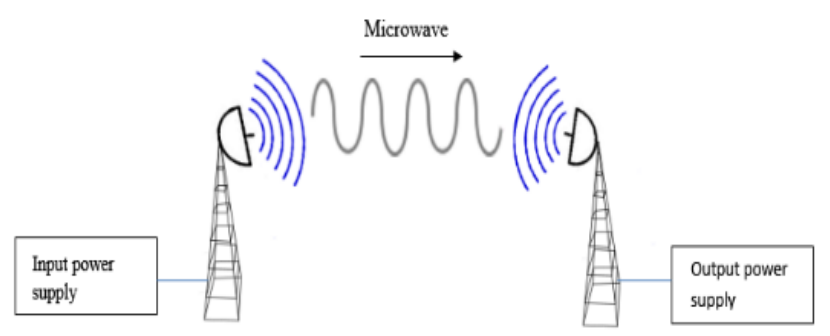

Figure 2: Electric energy is transferred to a strong beam of radio or microwave by a dish-like antenna, travels through the atmosphere and then received by another antenna which transfers it back to output power supply. the lamp. The lamp then looks like an original Edison lamp with a carbon filament [23].

- Rectenna was invented by Brown in 1964 which could efficiently convert microwaves to DC power, and the first wireless-powered aircraft demonstrated in 1964, a model helicopter powered by microwaves beamed from the ground $[24,25]$.

- In California 1975 Wireless high-power transmission using microwaves experiments in the tens of kilowatts have been performed at Goldstone [26-28].

- The first MPT experiment in space was carried out by Hiroshi Matsumoto's team in 1983. The experiment was called MINIX (Microwave Ionosphere Nonlinear Interaction Experiment) $[29,30]$.

- In 1987 fuel-free airplane flight experiment was succeeded by Canadian group with MPT which was called SHARP (Stationary High-Altitude Relay Platform) with $2.45 \mathrm{GHz}$ [31].

- Several field MPT experiments have been conducted over the years In Japan. A fuel-free flight experiment was conducted successfully by joint collaborative group using phased-array technology, which was referred to as the Microwave Lifted Airplane Experiment (MILAX) in 1992 [32].

- From the University of Auckland in New Zealand, Professor John Boys and Professor Grant Covic developed systems to transfer large amounts of energy across small air gaps in 1993 $[33,34]$. In Japan this system was practical used as the moving crane and the AGV non-contact power supply [35].

- In 1994-95 power company and universities made Ground-toGround MPT experiment [36].

- In 1997 at Grand Bassin on Reunion Island, Microwave Power Transmission experiment was conducted [37].

- A lightweight unmanned model plane powered by a laser beam was demonstrated NASA's Dryden Flight Research Center in 2003. Photocells from a beam of infrared light from a groundbased laser generated the small model plane's motor was powered by electricity, while a control system kept the laser pointed at the plane [38].

- Marin Soljačić along with other researchers at the Massachusetts Institute of Technology applied in electromagnetic theory, the wireless power transmission concept based on stronglycoupled resonators in November 2006 [39-41].

- A long-range Microwave Power Transmission demonstration was realized on one of the islands of Hawaii in May 2008. Managed Energy Technologies of the U.S organized the demonstration and involved the wireless transmission of energy [42].

- Researchers at the university of Korea Advanced Institute of Science and Technology (KAIST) have developed an electric transport system that is called Online Electric Vehicle, OLEV. The vehicles get power wirelessly from cables via non-contact magnetic charging that are kept under the surface of the road. To manage traffic congestion and to improve efficiency by reducing energy consumption, this technique is established. In 
July 2009 the researchers at the university of Korea Advanced Institute of Science and Technology successfully did an experiment to a bus by suppling $60 \%$ power over a gap of 12 centimeters (4.7 in) [43].

- Kyoto University's group experiment from an airship to ground with two phased-controlled magnetrons in 2009 [44].

- Hatem Zeine an American physicist, inventor demonstrated how wireless power transmission using phased array antennas can deliver electrical power up to 30 feet in 2013. It uses the same radio frequencies as $\mathrm{Wi}-\mathrm{Fi}[45,46]$.

- Researchers at the University of Washington experiment power over $\mathrm{Wi}-\mathrm{Fi}$, at ranges of up to 20 feet in 2015. They also experiment using $\mathrm{Wi}-\mathrm{Fi}$ that it can be used to wirelessly trickle-charge nickel-metal hydride and lithium-ion coin-cell batteries at distances of up to 28 feet $[47,48]$.

- Federal Communication Commission (FCC) certified the first mid-field radio frequency (RF) transmitter of wireless power in 2017 [49].

\section{Applications of Wireless Power Transmission}

\section{Transmission of power to the portable devices wirelessly}

In the below Figure 3 show the overall system is made using charger pad and the battery. To transfer energy from the charging pad to the battery each part has planar coils. The charging pad and battery can
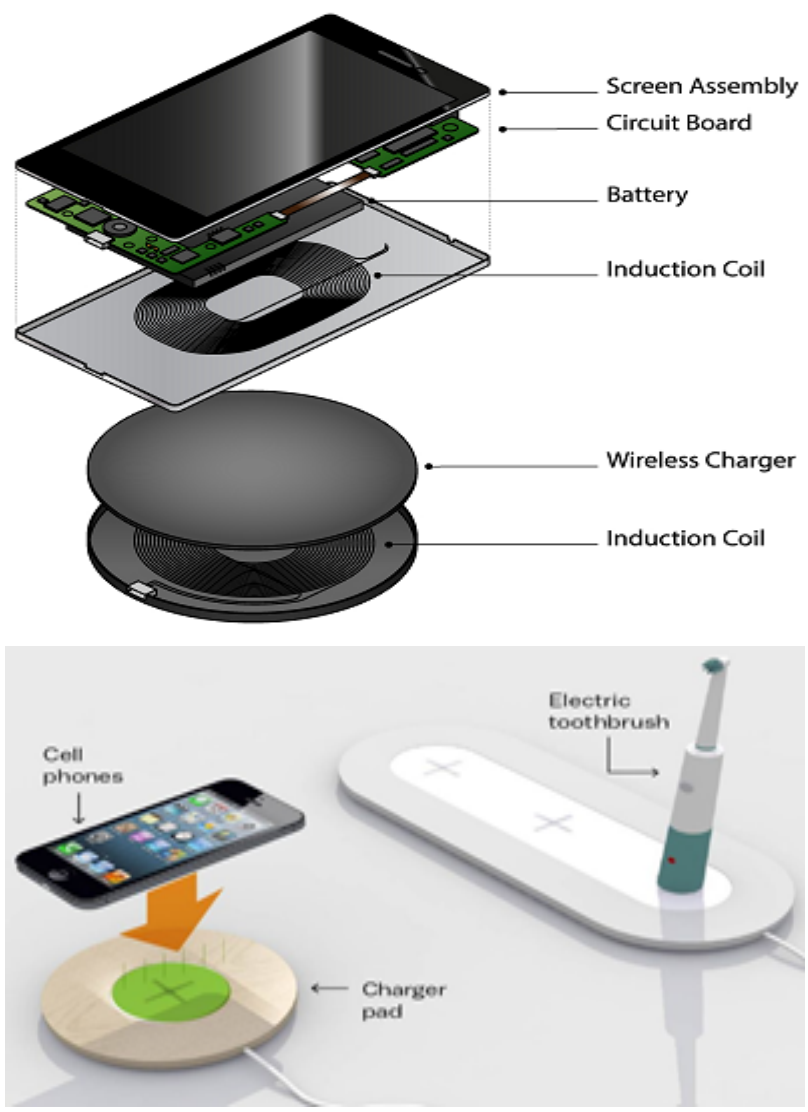

Figure 3: Wireless Charging of portable device using inductive coupling. communicate with each other cause the electrical energy is modulated. Before transmits full power to the battery, the charging pad verify that a valid battery is in place or not. This communication continues throughout the entire charging process to confirm the battery is still in place [50].

\section{Wirelessly charging of electric vehicle}

According to Figure 4 a charging pad sits on the ground, connected to a wall-mounted power adapter. All the car parks over it. On the backside of the car there is a receiver when charger detects the receiver within range, it automatically starts charging [51].

\section{Wirelessly charging of public transport}

Every electric bus has a wireless charging receiver. According to Figure 5 Wireless chargers are embedded in the hard surface of a road or under the road surface at regular intervals. When the bus is stopped no need to plug in or no need to connect with wireless chargers. It will automatically have charged. It's a motion bus. These kinds of buses are already tested in the UK, Italy, the Netherlands, and South Korea [50].

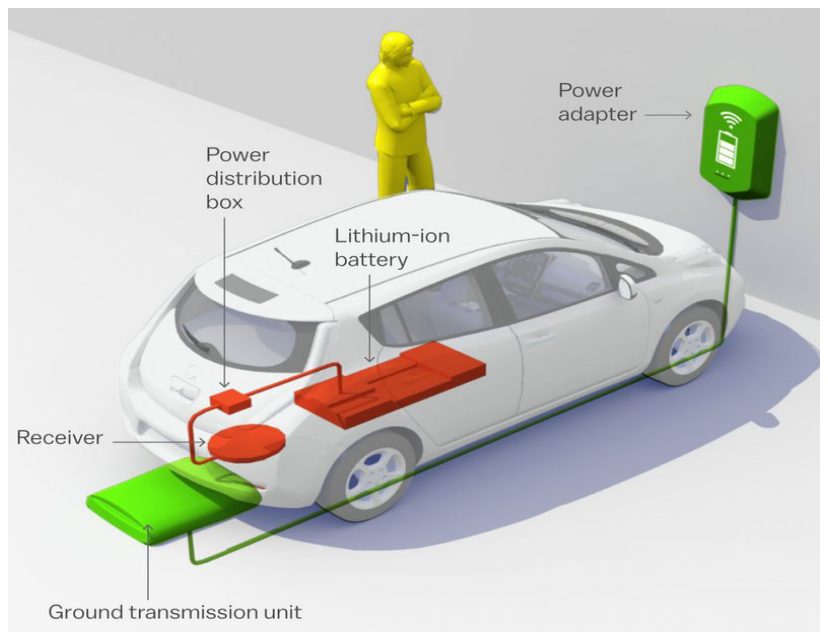

Figure 4: Wireless Charging of Electronic vehicle.

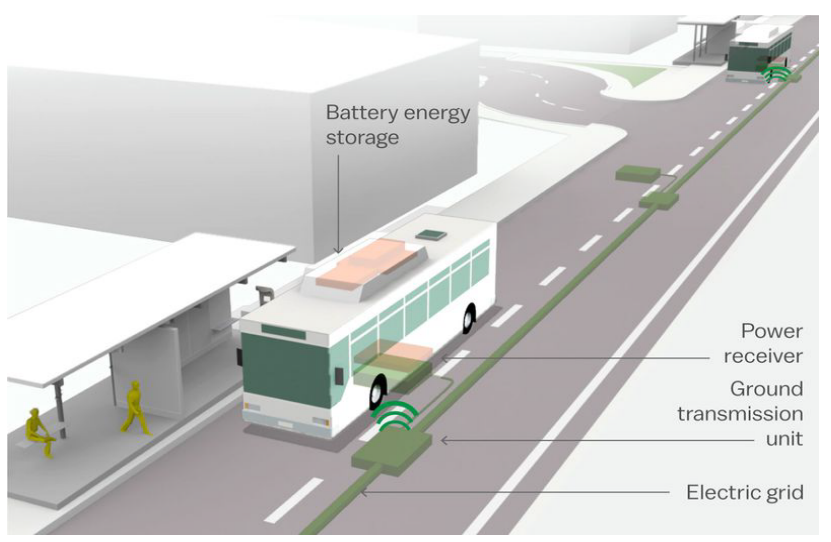

Figure 5: Wireless Charging of public bus. 


\section{Wirelessly charging lane for Self-driving electrical vehicle}

In the Figure 6 defines vehicles can simply return and park for a while to charge by using wireless charging pads in parking Garages, curbs, lanes, and for self-driving [51].

\section{Future scope of wireless power transfer technology}

In future we can use electric appliances by using electricity without wire. In the below, discussing some potential scope of using wireless power transfer technology.

\section{Solar Power Satellite}

Satellite with solar panel is used to capture maximum amount of solar energy from the sun in the space. Satellite consists of microwave transmitter which is used to convert power into microwave for transmission. According to Figure 7 transmitting microwave from the satellite present in space received by the microwave receiving antenna situated into the earth. This microwave receives antenna then convert microwave into electricity. Then this electricity can be used to power home and office etc.

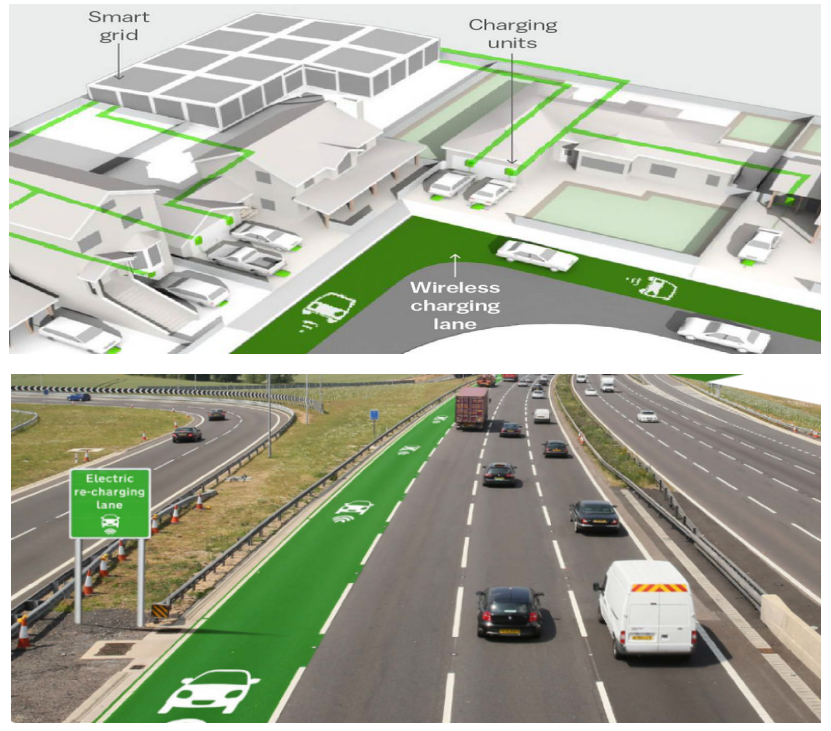

Figure 6: Wireless charging lane for self-driven Electric vehicle.

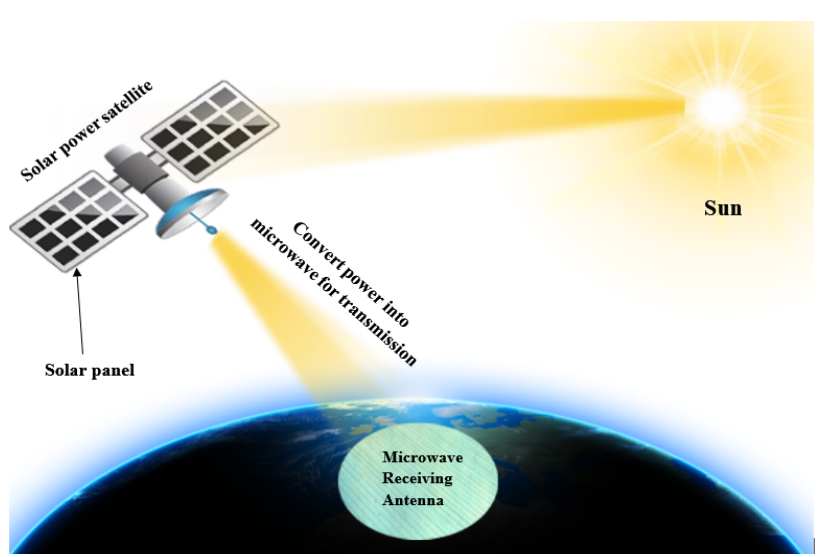

Figure 7: Wireless power transmission from space into the earth through solar power satellite.

\section{Wirelessly powered home appliances}

In future there will be a transmitting device inside home that will transmit power to all the home appliances such as Television, Laptop, Lamp, Iron, Sound Box, Fridge, Mobile etc. show in Figure 8. Transmitting device transmit power and all the appliances will receive that power through receiving devices set up inside into all appliances.

\section{Wirelessly charging of electric vehicle on way}

According to Figure 9 in future there will be no need to stop and charge the electrical vehicles. On the way charging can be done. In this concept power beam transmitter will be connected to highways, busy traffic areas with power source. which converts electricity into power beam and then that beam will transmitted to the electrical vehicle which consist power beam receiver that convert power beam into electrical power for the charging of battery inside the vehicle.

\section{Universal power source in emergency}

In an emergency or disaster situation where all the communication medium and power system has broken down. Communication immediately after a disaster situation is an important component of response and recovery; it connects affected people, families and communities with support system and other family members. In this situation an emergency power source may help to provide nessesary power source to power their communication devices so that they can easily connect with their family and rescue services as show in Figure 10. An universal power source consists of an airship built in power trasmittor which act as power source and drons; which consists of power receiving and trasmitting device which provide basic communication as well basic wireless power to the affected people.

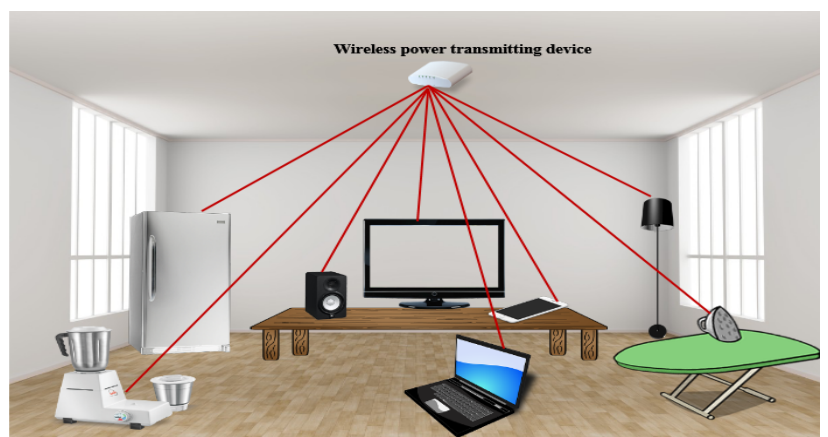

Figure 8: Wireless power transmission from transmitting device into the home appliances.

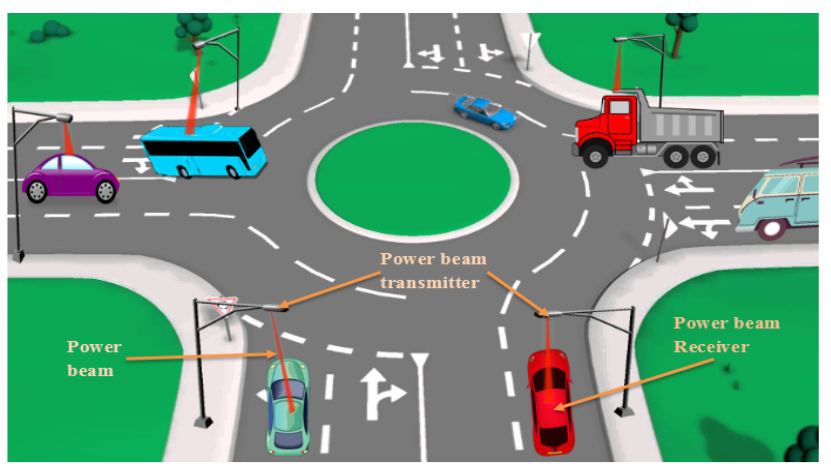

Figure 9: Wirelessly charging of electrical vehicle on the way. 


\section{Wirelessly powered train}

According to Figure 11 in future train may get power wirelessly. There will be no need to connects the train with wire. In this system a dual mode power receiver and transmitter will connect to the pole. Each station will have a pole with the dual mode transmitter and receiver. Power come from the power station that dual mode transmitter captures the power and transmit the power. By using dual mode transmitter power receive and transmit happen simultaneously. These powers will be received by the receiver that fixed in the roof of the train. In this process there is no need to use wire.

\section{Wirelessly power supply to house from power station}

In future clean and green power generation may be done using the renewable source of energy. Figure 12 defines power may be supplied to our houses wirelessly. Power transmitting antenna connected with the power supply providing station then power transmitting antenna convert electric power into microwave then transmit it to the nearest dual mode power receiving and transmitting antenna which transmit this microwave to nearest antenna which is connected nearest to the house. The house has its power receiving antenna which converts this microwave into electrical power. This electric power than utilize by the house.

\section{Wirelessly controlling drone to extinguish the fire}

In future drone may be used to extinguish the fire. Drone may carry the water pipe and set the pipe to exact location that will be controlling by the people using remote control system. Figure 13 defines drone may get the power from transmitter establish in the fire down car.

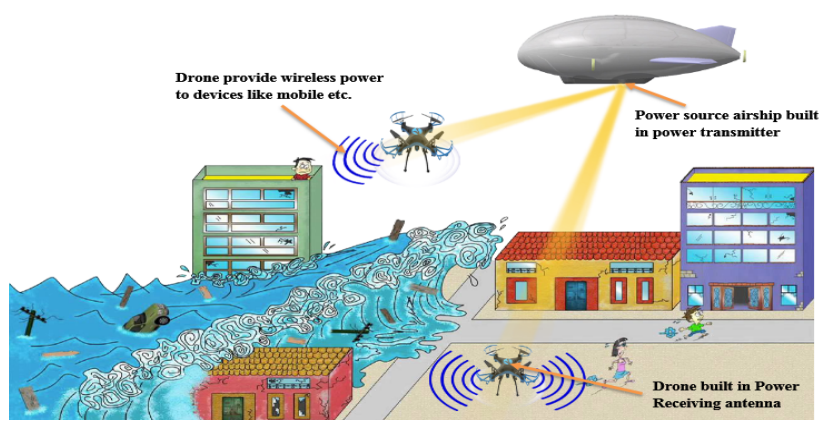

Figure 10: Communication through wireless power source in emergency.

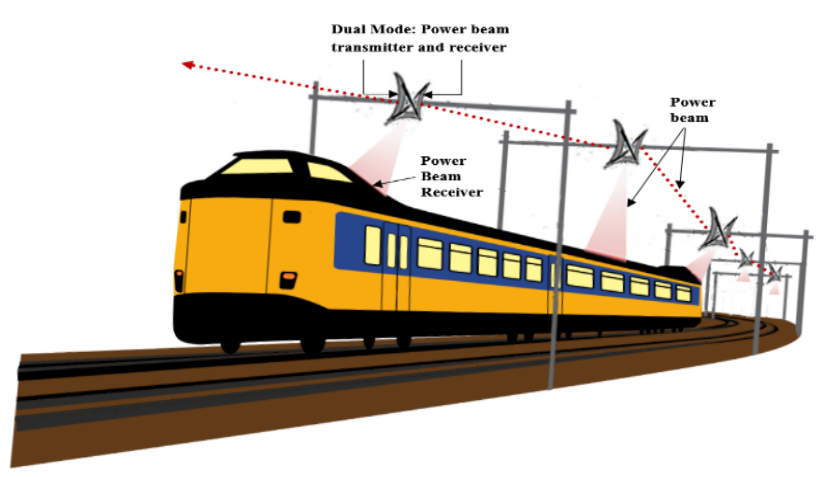

Figure 11: Future of wirelessly powered electric train

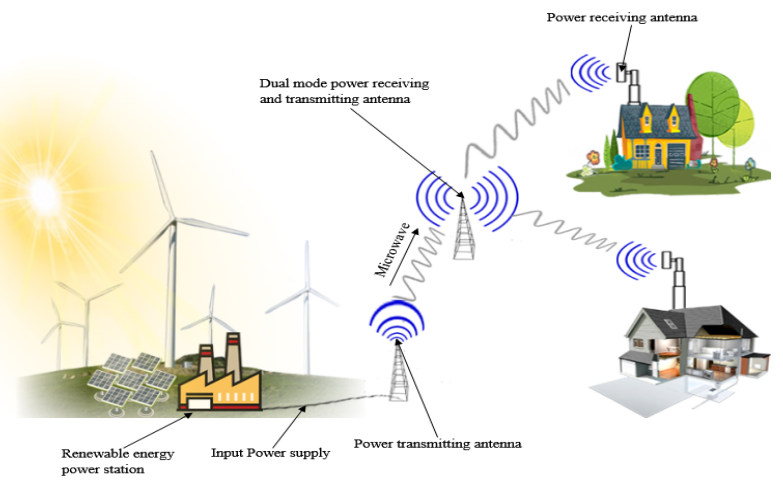

Figure 12: Wireless power supply to the house from green and clean power station.

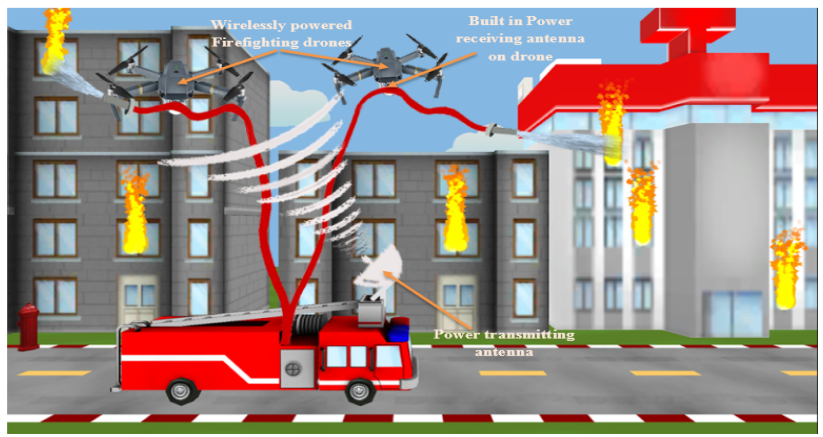

Figure 13: Firefighting drones getting its power wirelessly from firefighting vehicle.

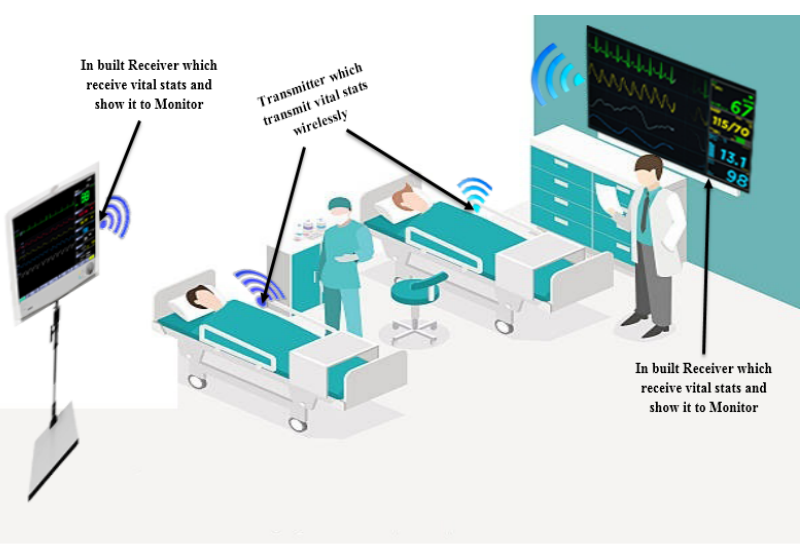

Figure 14: Wireless power transmission used for medical purpose.

Transmitter transmits power and drone will have a receiver device that will receive the power and work properly until the power has stopped. Drone is very useful because where people cannot reach drone can reach there and can capture pictures, videos of that area situation. In emergency, it is not possible to connect the drone with wire, so this process will be very useful. 


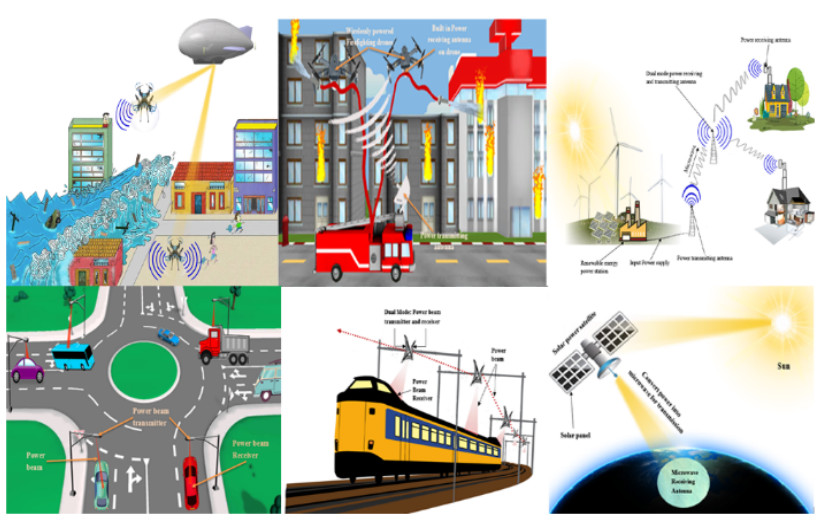

Figure 15: Wireless technology make a city smart city.

\section{Wireless power apply to medical devices}

In future wireless power supply in medical devices can be possible. There will be a transmitter that will be directly connected with power station. Figure 14 defines transmitter receives the signal from power station and transmit the signal continuously. The transmitting power receives by the receiver establishes in hospital and generates wireless electricity. By using this electricity medical devices will be performed simultaneously. There will be some electrical devices in patients hand these devices show the status of that patient. Their physical status will show in monitor. So, doctors can easily understand their condition and can take measurable step quickly.

\section{Wirelessly powered smart city}

According to Figure 15 a city can be a smart city using wireless technology. We can use power from power station without wire through transmitter and receiver. Transmitter transmit electricity from power station and a receiver receive the power and supply the power between houses, cars, trains, offices even emergency areas where wired technology is impossible to set up. By using wireless technology our environment will be carbon dioxide gas free. We get benefited because our environment will be clean and harmful gas free that emits from car, train or other vehicles.

\section{Conclusion}

Now a day, we are using technology wirelessly like our phone, which is a very big example of it but if we implement this method to use modern technology by using wireless method then our communication will be strong and smooth. In this paper, we have discussed about wireless power transmission technology and its various applications in our life. Moreover, we have presented and discussed the potential implementation of wireless power transfer technology to make our life easier.

\section{References}

1. Boca KN, Mickle MH, Sejmik E (2017) Multi-Disciplinary Challenges in Tissue Modeling for Wireless Electromagnetic Powering: A Review. IEEE Sensors Journal 17: 649-6509.

2. Waffenschmidt E, Staring T (2009) Limitation of Inductive Power Transfer for Consumer Applications. Conf Power Electron (EPE).

3. Yue Ma (2010) Wireless Energy Transfer. Stanford University, USA.

4. Hadley F (2007) MIT Demos Wireless Power Transmission. MIT Tech Talk.
5. Christoforidis G, Bourekas EC, Baujan M, Abduljalil AM, Kangarlu A, et al. (1999) High Resolution MRI of the Deep Brain Vascular Anatomy at 8 Tesla: Susceptibility-Based Enhancement of the Venous Structures. J Comput Assist Tomogr 23: 857-866.

6. Stephen BF (2014) Smart Grid: Communication-Enabled Intelligence for the Electric Power Grid. John Wiley \& Sons.

7. https://www.pcmag.com/encyclopedia/term/61262/wireless-charging

8. https://www.newscientist.com/article/mg22129534.900-wireless-charging-forelectric-vehicles-hits-the-road

9. Barrett J (1894) Electricity at the Columbian Exposition. R. R. Donnelly and Sons.

10. Landis G (1994) Laser Power Beaming. SPIE Proceedings 2121: 320.

11. https://www.ise.fraunhofer.de/en/business-areas/photovoltaics/iii-v-andconcentrator-photovoltaics/iii-v-epitaxy-and-solar-cells/laser-power-beamingpower-by-light.html

12. Sahai A, David G (2011) Optical wireless power transmission at long wavelengths. ICSOS.

13. Bett AW, Dimroth F, Lockenhoff R, Oliva E, Schubert J (2008) III-V solar cells under monochromatic illumination. IEEE Photovoltaic Specialists Conference.

14. Jonathan S (2008) Laser weapons: A distant target, CNET news.

15. Laser Weapons "Almost Ready?" Not!".

16. Drew H (2009) White Sands testing new laser weapon system.

17. Lasers Power Planes, Drones.

18. Gilbertson RG (2005) Riding a Beam of Light: NASA's First Space Elevator Competition Proves Highly Challenging.

19. Tesla N (1891) Experiments with Alternating Currents of Very High Frequency and Their Application to Methods of Artificial Illumination. AIEE, Columbia College, New York.

20. Experiments with Alternate Currents of High Potential and High Frequency, IEE Address, London, Tesla Resources, 1982.

21. On Light and Other High Frequency Phenomena, Franklin Institute Philadelphia, National Electric Light Association, St. Louis, March, 1893.

22. N Tesla (1897) Electrical transformer. No. 593,138: USA Patent.

23. Burns EE (1910) The Story of Great Inventions. Harper and Brothers, New York, pp: 229.

24. Anuradha T, Sunil G (2012) Wireless power Transmission: Applications and Components. IJERT 1: 1-8.

25. William CB (1984) The history of power transmission by radio waves. IEEE Transactions on Microwave Theory and Techniques.

26. Space Solar Energy Initiative. Space Island Group.

27. http://www.sspi.gatech.edu/wptshinohara.pdf

28. Matsumoto H, Hirata H, Hashino Y, Shinohara N (1995) Theoretical Analysis of Nonlinear Interaction of Intense Electromagnetic Wave and Plasma Waves in the lonosphere. Electron Commun Jpn 78: 104-11.

29. Matsumoto H, Hashino $Y$, Yashiro H, Shinohara N, Omura Y (1995) Computer Simulation on Nonlinear Interaction of Intense Microwave with Space Plasmas. Electron Commun Jpn 78: 89-103.

30. Schlesak JJ, Alden A, Ohno TA (1988) Microwave powered high altitude platform. IEEE MTTS Int Microw Symp.

31. Matsumoto H (1993) MILAX Airplane Experiment and Model Airplane. 12th ISAS Space Energy Symposium, Tokyo, Japan, March.

32. Ushijima M, Yuasa $H$, Ogino $G$ (2015) Simulation of, and experiment regarding wireless power transfer using a method combining elements of magnetic induction and magnetic resonance: Theory and verification of a model of wireless power transfer having a resonant structure in only the secondary side. IEICE Technical Report 13: 7-12. 
33. Breakthrough was finally found in the wireless power transfer - Improve efficiency and robustness by slightly modifying the problem of magnetic resonance theory. Green Electronics, $C Q$ publishing 19: 52-69.

34. Non-Contact Power Supply Transport System Technology. DAIFUKU AGV Since 1993

35. Shinohara N, Matsumoto H (1998) Dependence of dc Output of a Rectenna Array on the Method of Interconnection of Its Array Element. Electr Eng Jpn 125: 9-17.

36. Lan Sun Luk JD, Celeste A, Romanacce P, Kuang Sang LC, Gatina JC (1997) Point-To-Point Wireless Power Transportation In Reunion Island. Inter Astronautical Congress, Turin, Italy.

37. https://www.nasa.gov/centers/armstrong/news/FactSheets/FS-087-DFRC. html

38. Wireless electricity could power consumer, industrial electronics. MIT News, 2006.

39. Dumé B (2006) Gadget recharging goes wireless. Physics World.

40. Evanescent coupling could power gadgets wirelessly. New Scientist, 2006.

41. John MC (2011) Space Solar Power - Results of the First International Assessment. Cosmic Study Report from the International Academy of Astronautics.
42. Paul R (2009) Korean electric vehicle solution. New Atlas.

43. Mitani T, Yamakawa H, Shinohara N, Hashimoto K, Kawasaki S, et al. (2010) Demonstration experiment of microwave power and information transmission from an airship. Proc. 2nd Int. Symp. Radio System and Space Plasma, pp: 157-160.

44. Cota system transmits power wirelessly at up to 30 feet. New atlas.

45. Darrell E (2013) Cota By Ossia Aims To Drive A Wireless Power Revolution and Change How We Think About Charging.

46. Talla V, Kellogg B, Ransford B, Naderiparizi S, Gollakota S (2015) Powering the Next Billion Devices with Wi-Fi.

47. First Demonstration of a Surveillance Camera Powered by Ordinary Wi-Fi.

48. Energous Receives Industry-First FCC Certification for Over-the-Air, Powerat-a-Distance Wireless Charging. Energous Corporation (WATT), Energous Corporation, 2018.

49. Wireless Power Charging Technologies. EPEC.

50. David R, Javier Z (2017) Wireless charging for cars, phones, and everything else electric is coming soon. VOX.

51. Jeremy W (2017) Transport innovation of the week: electric charging lanes. Make Wealth History. 